ARTICLE

\title{
Xanthine oxidoreductase regulates macrophage IL1 $\beta$ secretion upon NLRP3 inflammasome activation
}

Annette Ives ${ }^{1}$, Johji Nomura,2, Fabio Martinon ${ }^{3}$, Thierry Roger ${ }^{4}$, Didier LeRoy ${ }^{4}$, Jeffrey N. Miner ${ }^{5}$, Gregoire Simon ${ }^{1}$, Nathalie Busso ${ }^{1, \star} \&$ Alexander So ${ }^{1, \star}$

Activation of the NLRP3 inflammasome by microbial ligands or tissue damage requires intracellular generation of reactive oxygen species (ROS). We present evidence that macrophage secretion of IL1 $\beta$ upon stimulation with ATP, crystals or LPS is mediated by a rapid increase in the activity of xanthine oxidase (XO), the oxidized form of xanthine dehydrogenase, resulting in the formation of uric acid as well as ROS. We show that $\mathrm{XO}$-derived ROS, but not uric acid, is the trigger for IL1 $\beta$ release and that $\mathrm{XO}$ blockade results in impaired IL1 $\beta$ and caspase1 secretion. $X O$ is localized to both cytoplasmic and mitochondrial compartments and acts upstream to the PI3K-AKT signalling pathway that results in mitochondrial ROS generation. This pathway represents a mechanism for regulating NLRP3 inflammasome activation that may have therapeutic implications in inflammatory diseases.

\footnotetext{
${ }^{1}$ Rheumatology Laboratory, Centre Hospitalier Universitaire Vaudois, Ave Pierre Decker 4, 1011 Lausanne, Switzerland. ${ }^{2}$ Pharmaceutical Development Research Laboratories, Teijin Institute for Bio-Medical Research, Teijin Pharma Limited, Hino, 1918512 Tokyo, Japan. ${ }^{3}$ Department of Biochemistry, University of Lausanne, chemin des Boveresses 155, 1066 Epalinges, Switzerland. ${ }^{4}$ Infectious Diseases laboratory, Centre Hospitalier Universitaire Vaudois, 1011 Lausanne, Switzerland. ${ }^{5}$ Ardea Biosciences, San Diego, 92121 California, USA. * These authors equally contributed to this work. Correspondence and requests for materials should be addressed to A.S. (email: alexanderkai-lik.so@chuv.ch).
} 
T he inflammasome is key in regulating macrophage interleukin (IL)- $\beta$ secretion in response to pathogenassociated molecular patterns (PAMPs) and damageassociated molecular patterns (DAMPS). The NLRP3 inflammasome, composed of NLRP3, ASC and caspase1, can be activated by soluble and particulate PAMPs (such as lipopolysaccharide (LPS)) and DAMPs (such as urate and calcium crystals, nigericin and adenosine triphosphate (ATP)), resulting in active caspase1 that cleaves proIL1 $\beta$ to the secreted $\mathrm{p} 17 \mathrm{kD}$ form of IL1 $\beta$. Multiple pathways have been found to regulate inflammasome activation: cellular and mitochondrial reactive oxygen species (ROS) ${ }^{1}$, inflammasome translocation to the mitochondria by MAVS ${ }^{2}$, cathepsin B release from phagolysosomes ${ }^{3}$, activity of the cytosolic protein $\mathrm{PKR}^{4}$ and changing cytosolic levels of $\mathrm{K}^{+}$ (ref. 5) and $\mathrm{Ca}^{2+}$ (ref. 6). Among these pathways, ROS generation is shared by a number of different inflammasome triggers, such as LPS, urate crystals and ATP, but the source of ROS has not been clearly established. Initial studies implicated the NADPH oxidase (NOX) complex ${ }^{7,8}$, but more recent work found that macrophages derived from knockout mice for the NOX1, NOX2 or NOX4 component of this complex did not impair IL1 $\beta$ secretion, and macrophages derived from patients with chronic granulomatous disease due to mutations of this complex were still capable of secreting IL1 $\beta$ in response to DAMPs $^{1,3,9}$. Mitochondrial ROS could be an alternative intracellular source, and there is data linking mitochondrial stress to ROS production as well as autophagy ${ }^{10,11}$.

Another potential source of cellular ROS is the enzyme xanthine oxidoreductase (XOR), but its role has not been investigated. XOR is a key enzyme in the catabolism of purines into uric acid (UA) that is then further broken down to allantoin in mammals that possess the enzyme uric oxidase (or uricase). The xanthine oxidase (XO) form of XOR utilizes oxygen as a substrate to break down hypoxanthine and xanthine to UA and produces superoxide and hydrogen peroxide as part of the reaction, and is expressed predominantly during cell stress or upon immune activation. A number of clinical and experimental studies have suggested that XOR activity has pro-inflammatory effects and can mediate cardiovascular and endothelial dysfunction $^{12,13}$, and inhibition of XOR by allopurinol has been shown to reduce hypertension ${ }^{14}$ as well as improving cardiac function ${ }^{15}$.

UA itself also has both anti-inflammatory as well as proinflammatory properties ${ }^{16}$, but the mechanisms linking XOR activity to inflammation remain to be determined. Studies have shown that UA plays a role in innate immune responses, and can act as an adjuvant when released from dying cells, and take part in plasmodium-induced inflammatory responses and the induction of $\mathrm{Th}_{2}$ responses in asthma ${ }^{17-20}$. This raises the question which product, ROS or UA, is responsible for these effects. Allopurinol, an XOR inhibitor, decreased IL1 $\beta$ secretion in response to toll-like receptor (TLR)7/8 stimulation or soluble hemozoin (HZ) administration and inhibited urate production ${ }^{21,22}$. However, other studies showed that the addition of uricase failed to block inflammasome-dependent IL1 $\beta$ secretion, suggesting that other mechanisms beside uric-acid production are involved ${ }^{, 23,24}$.

We hypothesize that XO-dependent generation of ROS mediates NLRP3 inflammasome activation and thus, we studied the role of XOR in DAMP- and PAMP-elicited IL1 $\beta$ responses. Our results demonstrate that XO is a major source of ROS in macrophages and is an important component of innate inflammatory signalling.

\section{Results}

Crystalline activators require XO to induce IL1ß secretion. We previously demonstrated that basic calcium phosphate crystals (including octacalcium phosphate (OCP)) elicit massive IL1 $\beta$ secretion in primed bone-marrow-derived macrophages (BMDMs) via an NLRP3-dependent mechanism in vitro ${ }^{25}$. We showed that this process was accompanied by increased intracellular urate levels and $\mathrm{XO}$ activity (as assessed by $\mathrm{H}_{2} \mathrm{O}_{2}$ production) (Fig. 1a). In vivo, elevated urate and $\mathrm{XO}$ activity levels were also correlated to IL1 $\beta$ in peritoneal washes taken from mice during OCP-induced peritonitis (Fig. 1a). Similarly, Alum and $\mathrm{HZ}$ stimulation of BMDMs induced $\mathrm{XO}$ activity early on during stimulation, at $2 \mathrm{~h}$ (Fig. 1b).

To demonstrate that $\mathrm{XO}$ activity is required for inflammasome activation and IL1 $\beta$ secretion, we tested the effects of XOR inhibition. Using short interfering RNA (siRNA) to impair XOR expression (knockdown efficiency was determined to be $40 \pm 8.4 \% ; P \leq 0.0001, t$-test by quantitative reverse transcriptase (qRT)-PCR, and $58 \pm 3.3 \% ; \quad P \leq 0.005, \quad t$-test by the XO activity assay) we observed a significant reduction in secreted IL1 $\beta$ in primed and crystal-stimulated BMDM (Fig. 1c). Treatment of primed BMDM with allopurinol or febuxostat (two inhibitors targeting both $\mathrm{XO}$ and xanthine dehydrogenase (XDH) forms ${ }^{26,27}$, prior to crystal stimulation, yielded similar results (Fig. 1d). Their inhibitory capacities were similar to that observed with the ROS inhibitor apocynin (Fig. 1d). As febuxostat also inhibited IL1 $\beta$ secretion in human THP1 cells and primary human monocyte-derived macrophages, we confirmed that this was a general mechanism (Fig. 1e; Table 1). Impaired phagocytosis was excluded, as febuxostat did not affect the number of latex beads taken up by $\mathrm{M} \phi$ (percentage uptake $63.2 \pm 6.6 \%$ with febuxostat versus $68.5 \pm 1.8 \%$ in control cells).

Using the in vivo peritonitis model, we confirmed XOR inhibition by allopurinol in OCP-treated mice decreased IL1 $\beta$ and urate levels in the peritoneal lavage, while cellular recruitment remained unchanged (Fig. 1f).

XOR activity mediates caspase 1 processing. As crystal-induced IL1 $\beta$ secretion in macrophages relies on NLRP3 inflammasome assembly and the formation of active caspase1, we examined the role of XOR. We confirmed that febuxostat reduced intracellular caspasel activity after OCP stimulation (non-treated: $176.63 \pm 5.811$; febuxostat: $55.20 \pm 39.269$ relative fluorescence units (RFUs) $\mathrm{mg}^{-1}$ of protein; $P \leq 0.05, t$-test). Experiments on primed, but unstimulated BMDMs showed no decrease in the intracellular pool of proIL1 $\beta$ after febuxostat treatment $\left(3,342.50 \pm 427.50\right.$ and $3,148.75 \pm 71.25 \mathrm{pg} \mathrm{ml}^{-1}$, respectively) in BMDM at $4 \mathrm{~h}$. Similar results were found in THP1 cells (Fig. 1e). Yet, febuxostat did impact the levels of processed caspasel and IL1 $\beta$ secreted from the cells (Fig. 1e). Taken together, these results demonstrate that XOR plays an important role in the generation of active caspase1, which allows for IL1 $\beta$ to be cleaved and secreted outside the cell.

We tested the effects of febuxostat on OCP-induced IL1 $\beta$ secretion by human macrophages. Using two different forms of priming (LPS ultrapure and Pam3Cys), OCP crystals induced IL1 $\beta$ release and this was significantly impaired when febuxostat was added (Table 1).

The effects of XOR are not mediated by urate. As UA can act as an immune adjuvant ${ }^{17,28}$, we evaluated whether our responses could be due to XOR generation of urate. Despite increased intracellular urate, we did not detect any urate in the culture supernatants, nor did extracellular uricase treatment affect secreted IL1 $\beta$ levels, with the exception of monosodium urate (MSU) stimulation. This was due to crystal degradation (Fig. 2a). 


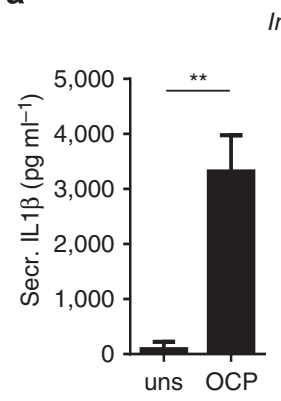

In vitro BMDM stimulation
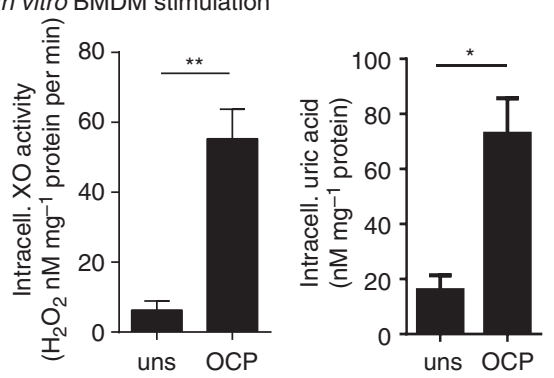

In vivo crystal induced peritonitis
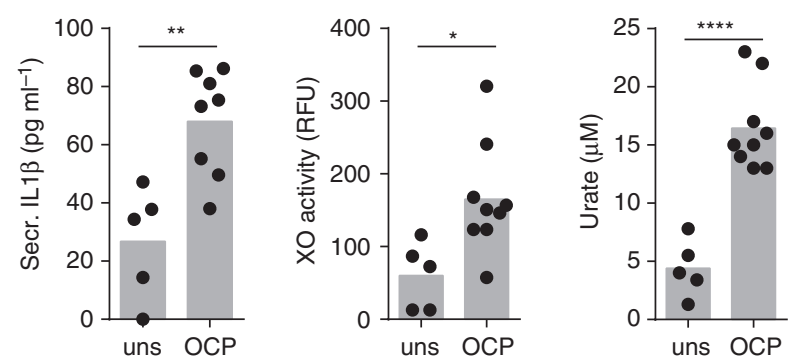

d

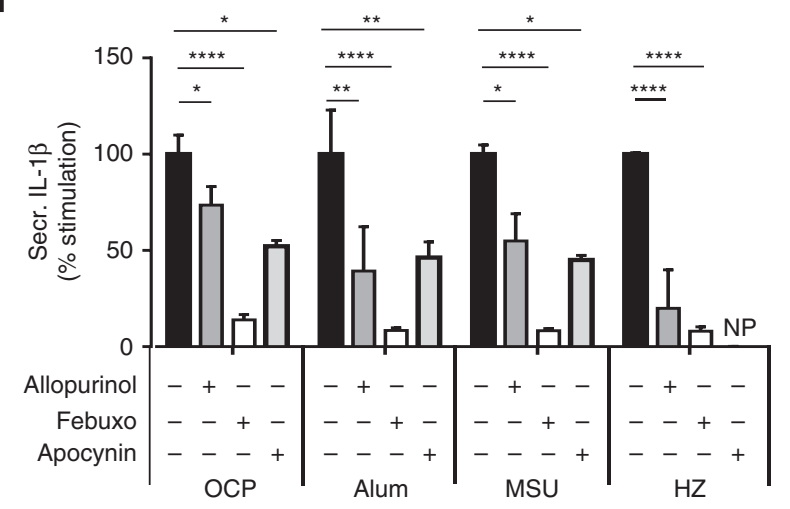

f

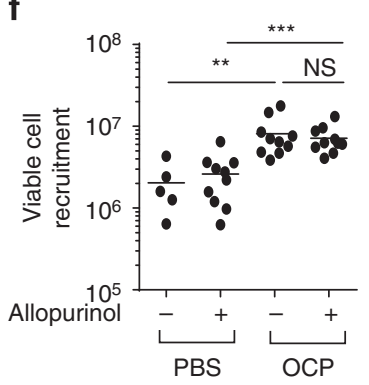

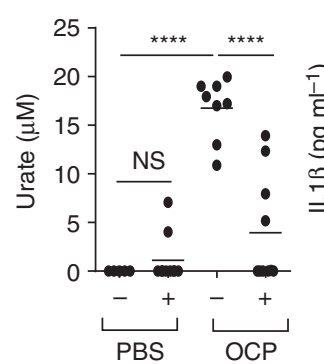

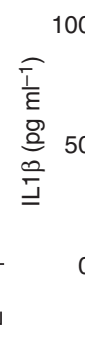

b

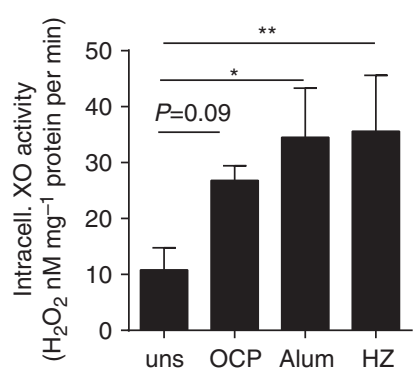

C

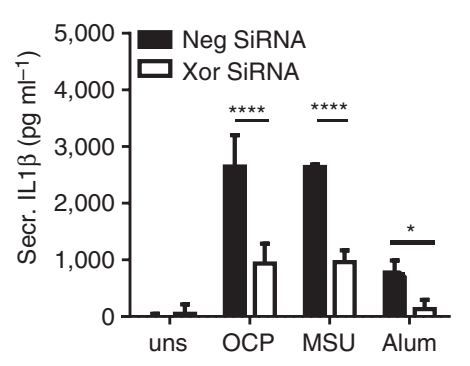

e
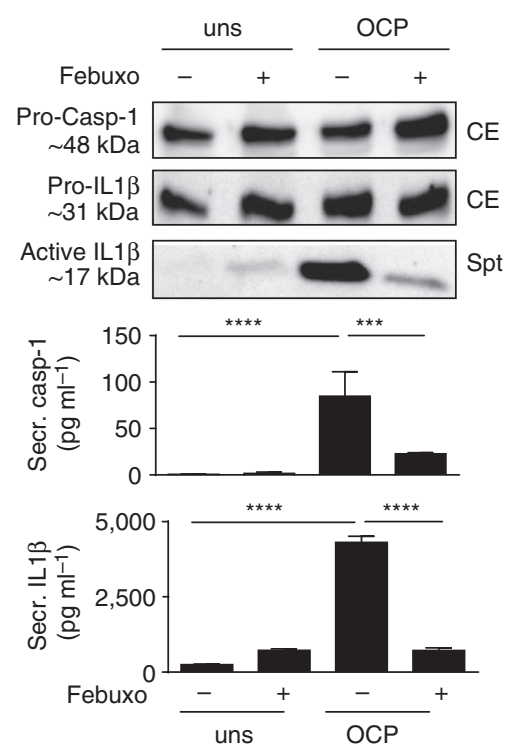

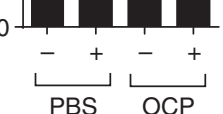

Figure 1 | XOR is involved in caspase1-dependent secretion of IL1 1 in macrophages stimulated with microcrystals. In vitro C57BL/6 BMDM (Pam3Cys (P3C) or LPSup primed), and THP1 (PMA primed) were stimulated with OCP and MSU at $250 \mu \mathrm{g} \mathrm{ml}^{-1}$, Alum-500 $\mu \mathrm{g} \mathrm{ml}^{-1}$ and HZ-200 $\mu \mathrm{g} \mathrm{ml}-1$.

IL1 $\beta$ protein was measured by ELISA in supernatants; intracellular $X O$ and UA measured on protein extracts by activity tests. (a) Upper panel: $P 3 C$ primed, OCP-stimulated BMDM. Lower panel: In vivo OCP-induced peritonitis. Levels of IL1 $\beta, X O$ and UA measured in peritoneal washes of individual mice.

(b) XO activity measured in LPSup primed, crystal-stimulated BMDM at $2 \mathrm{~h}$. (c) IL1 $\beta$ measured in XOR siRNA, or control NegSiRNA-transfected BMDM that were P3C primed. (d) BMDM were pretreated with XOR inhibitors (Allopurinol $250 \mathrm{~g} \mathrm{ml}^{-1}$, Febuxostat $200 \mu \mathrm{M}$ ) and Apocynin (2.5 mM), extracellular IL1 $\beta$ protein levels quantified and expressed as percentage of stimulation of inhibitor-treated versus non-treated cells. (e) Protein sizes of proCaspase1 and prolL1 $\beta$ in cell extracts (CEs), and active IL1 $\beta$ in the supernatants (spts) by western blot, secreted IL1 $\beta$ and caspase1 by ELISA. (f) In vivo, mice were pretreated with Allopurinol-500 $\mu \mathrm{g}$ per mouse $30 \mathrm{~min}$ prior to OCP-1 mg per mouse or PBS control intraperitoneal injection. After $6 \mathrm{~h}$, peritoneal washes were obtained (two pooled experiments). Viable cells were counted and urate, and IL1 13 measured. Unless stated, experiments were performed at $6 \mathrm{~h}$ and data are representative of at least two experiments. Results are expressed as mean \pm s.e.m. Significance was determined at ${ }^{\star} P \leq 0.05$, ${ }^{\star \star} P \leq 0.01,{ }^{\star \star \star} P \leq 0.005$ and ${ }^{\star \star \star \star} P \leq 0.0001$ by analysis of variance $(\mathbf{b}, \mathbf{d}-\mathbf{f})$ or the $t$-test $(\mathbf{a}, \mathbf{c})$. NP, not performed; NS, not significant. 
Table 1 | XOR inhibition impairs OCP-induced IL1ß secretion in human macrophages.

\begin{tabular}{|c|c|c|c|c|}
\hline \multirow{2}{*}{$\begin{array}{l}\text { Macrophages } \\
\text { Subject }\end{array}$} & \multicolumn{4}{|c|}{ 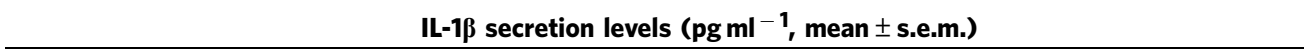 } \\
\hline & Priming & Stimulus & Non-treated & Febuxostat \\
\hline \multirow[t]{2}{*}{1} & Pam3Cys & OCP & $228.98 \pm 98.57$ & $46.46 \pm 12.93^{\star \star \star t}$ \\
\hline & LPSup & OCP & $281.07 \pm 38.06$ & $22.32 \pm 24.41^{\star \star \star}$ \\
\hline 2 & LPsup & OCP & $315.43 \pm 1.16$ & $47.12 \pm 2.11^{\star \star}$ \\
\hline \multirow[t]{2}{*}{3} & Pam3Cys & OCP & $1,221.35 \pm 20.51$ & $107.43 \pm 11.81^{\star \star \star \star}$ \\
\hline & LPsup & OCP & $48.23 \pm 8.17$ & Not induced \\
\hline
\end{tabular}

IL1 $\beta$, interleukin-1B; M-CSF, macrophage colony-stimulating factor; OCP, octacalcium phosphate; PBMC, peripheral blood mononuclear cell; TLR, toll-like receptor; XOR, xanthine oxidoreductase. Human PBMC-derived monocytes were differentiated into $M \phi \sigma$ with $50 \mathrm{ng} \mathrm{ml}^{-1} \mathrm{M}$-CSF. Cells were primed with TLR agonists, pretreated with febuxostat $200 \mu M$ and stimulated with OCP $250 \mu \mathrm{g} \mathrm{ml}^{-}$ for $6 \mathrm{~h}$. IL $1 \beta$ in supernatants was measured. Results expressed as the mean \pm s.e.m. of independent stimulations. Statistical significance determined at ${ }^{\star \star} P \leq 0.01$, ${ }^{\star \star \star} P \leq 0.005$, ${ }^{\star \star \star \star} P \leq 0.0001$ by the $t-$ test.
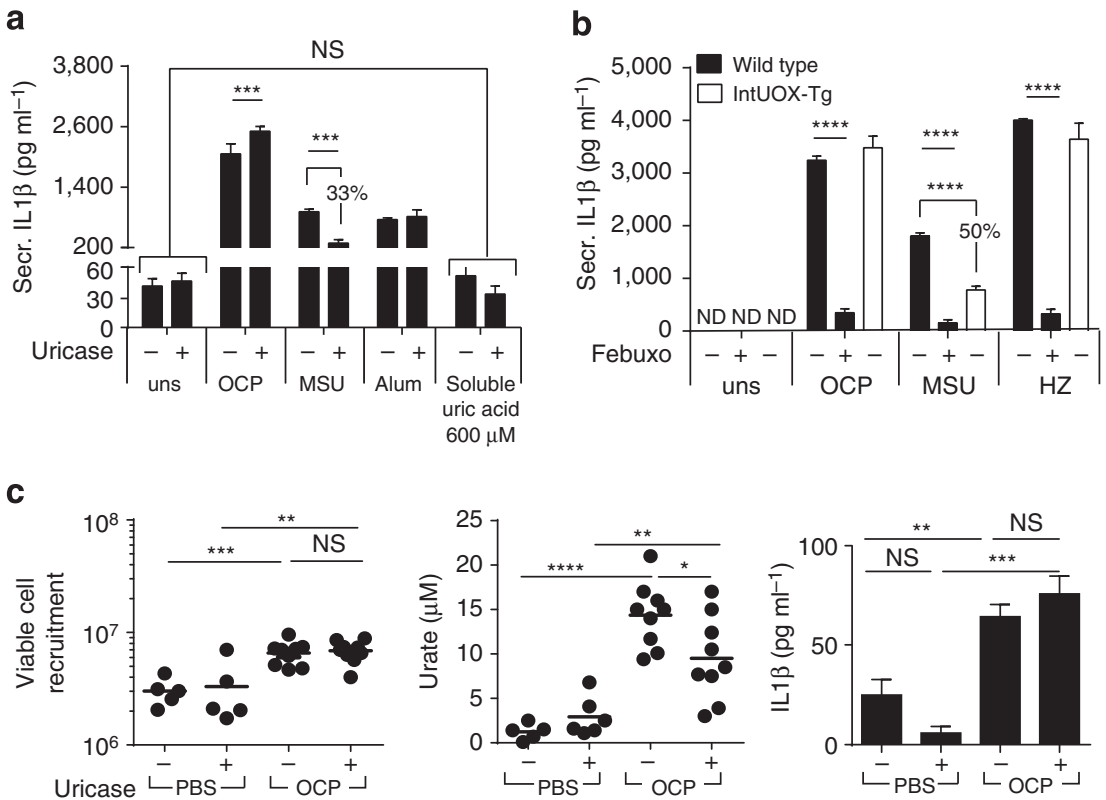

Figure 2 | Urate generated by XOR is not the mediator of inflammasome responses in crystal-stimulated macrophages. (a,b) In vitro C57BL/6 or intUOX-Tg-derived BMDM (Pam3Cys primed), pretreated with uricase-10 $\mu \mathrm{g} \mathrm{ml}^{-1}$ and XOR inhibitor febuxostat-200 $\mu \mathrm{M}$, were stimulated with OCP or MSU at $250 \mu \mathrm{g} \mathrm{ml}^{-1}$, Alum- $500 \mu \mathrm{g} \mathrm{ml}^{-1}, \mathrm{HZ}-200 \mu \mathrm{g} \mathrm{ml}{ }^{-1}$ or soluble urate at $600 \mu \mathrm{M}$. Experiments were performed at $6 \mathrm{~h}$; data are representative of at least two experiments. (c) Mice were pretreated with uricase-20 $\mu \mathrm{g}$ per mouse. OCP or PBS injected. After $6 \mathrm{~h}$, peritoneal washes were obtained, viable cells counted, and urate and IL1 $\beta$ measured in cell-free washes (two pooled experiments). Results are expressed as mean \pm s.e.m. Significance was determined at ${ }^{\star} P \leq 0.05,{ }^{\star \star} P \leq 0.01,{ }^{\star \star \star} P \leq 0.005$ and ${ }^{\star \star \star \star} P \leq 0.0001$ by analysis of variance. ND, not detectable; NS, not significant.

As the accumulated urate was retained within the cell, we stimulated BMDM from transgenic uricase mice (intUOX-Tg) with crystals ${ }^{28}$; no change in IL1 $\beta$ secretion was found (Fig. $2 \mathrm{~b}$ ). This was despite the results that demonstrated that BMDM derived from UOXTg mice did indeed overexpress the UOX gene by qRT-PCR as compared with wild-type cells (41.3 \pm 6.01 versus $1 \pm 0.15$, respectively, mean \pm s.e.m.). Uricase treatment in mice, unlike experiments with allopurinol, failed to impact IL1 $\beta$ levels produced in crystal-induced peritonitis (Figs 1f and 2c).

Finally, as very little is known about the effects of soluble urate and urate transport on immune responses in macrophages, we investigated this using BMDMs. Administration of high concentrations of soluble urate to mimic conditions seen in hyperuricemia in man (at $600 \mu \mathrm{M}$ ), filtered to exclude particulates, did not activate primed BMDM (Fig. 2a). The capacity of BMDM to transport urate across the membrane was also studied. We found BMDM had a limited capacity to take up extracellular soluble urate in a $\mathrm{C}^{14}$-radiolabelled assay (Supplementary Fig. 1a). A positive control hURAT1-transfected cell line confirmed that our assay was indeed functional (Supplementary Fig. 1a). Interestingly, BMDMs express a specific urate transporter gene profile, with only Glut9 being expressed at a significant level. No Urat1 and only weak expression of Abcg2 was detected by qRT-PCR (Supplementary Fig. 1b). Given these results, we did not investigate the protein expression of urate transporters in BMDM. All together, these results exclude a direct effect of soluble urate as the trigger for IL1 $\beta$ release, and favours a mechanism involving XORdependent ROS production.

XO mediates inflammatory signalling by ROS generation. Previous studies and our own work demonstrated a role for ROS scavengers in crystal-induced IL1 $\beta$ response, as NAC or 
apocynin addition impaired IL1 $\beta$ release. Thus, we theorized that XO could be the potential source of ROS in our model. Two different assays were used. Significant reductions of superoxide were observed after febuxostat treatment using the dihydroethidium (DHE) assay, similar to the reductions observed with apocynin (Fig. 3a; Supplementary Fig. 2a), while allopurinol reduced $\mathrm{H}_{2} \mathrm{O}_{2}$ generation by the luminol assay (Fig. 3b).

The relative contribution of $\mathrm{XO}$ and $\mathrm{XDH}$ activities within the cell was assessed using the pterin assay after crystal stimulation. We found that crystal stimulation increased the percentage of $\mathrm{XO}$. XO activity was measured in the presence of pterin alone, while total XOR activity was measured using both pterin and methylene blue (that replaces the NAD + electron receptor ${ }^{29}$ (Fig. 4a). Cellular responses to XO-generated superoxide require post-translational modification of the protein, but this can be coupled with increases in the intracellular protein pool. However, no modulation in XOR at the RNA transcript or protein level was observed (Fig. 4b,c). There was also no evidence of proteolytic transformation from the native $145 \mathrm{kDa}$ to the truncated $85-\mathrm{kDa}$ form by western blot (Fig. 4d). This suggests increased XO activity is due to reversible modification of XOR to generate the $\mathrm{XO}$ form of the enzyme. In support of this, we found that addition of the antioxidant dithiothreitol to BMDM lysates resulted in a decreased percentage of XO activity relative to total XOR activity in BMDM as compared with non-treated controls (73.7 versus $17.9 \%$, respectively). Altogether, these results suggest

a

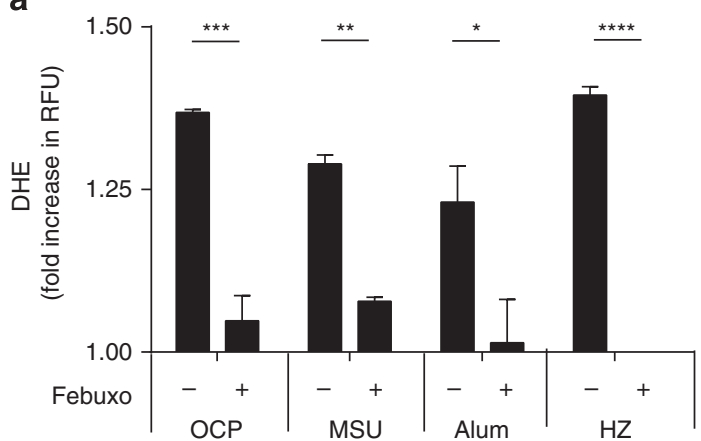

b

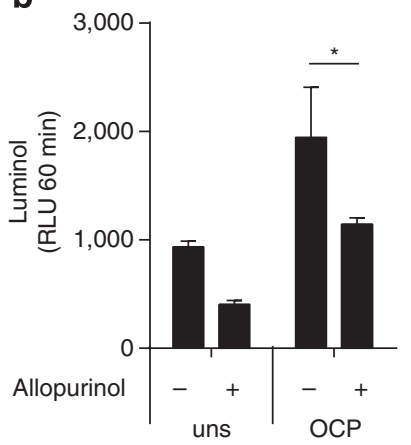

Figure 3 | Crystal-induced IL1及 secretion is mediated by ROS. In vitro BMDM (Pam3Cys primed) were pretreated with XOR inhibitors: febuxostat, $200 \mu \mathrm{M}$ and allopurinol, $500 \mu \mathrm{g} \mathrm{ml}^{-1}$ and stimulated with OCP or MSU at $250 \mu \mathrm{g} \mathrm{ml}^{-1}$, Alum-500 $\mathrm{g} \mathrm{ml}^{-1}$ and $\mathrm{HZ}-200 \mu \mathrm{g} \mathrm{ml}^{-1}$. (a) Superoxide was measured with dihydroethidium (DHE), results expressed as fold increase in relative fluorescence units (RFUs) at $T=120 \mathrm{~min}$ over $T=0$. (b) ROS measured by luminol, data obtained by relative luminescence units (RLUs) at $T=60 \mathrm{~min}$. Data are representative of at least two experiments. Results are expressed as mean \pm s.e.m. Significance was determined at ${ }^{\star} P \leq 0.05$, ${ }^{\star \star} P \leq 0.01,{ }^{\star \star \star} P \leq 0.005$ and ${ }^{* \star \star \star} P \leq 0.0001$ by the $t$-test for all panels. that XO activity in crystal-stimulated BMDM was most likely due to reversible sulfhydryl modification of $\mathrm{XDH}$ to $\mathrm{XO}$ that does not change the molecular weight of the protein.

XO induces mitochondrial ROS via the PI3K-AKT-mTOR pathway. The PI3K-AKT-mTOR pathway is implicated in ROSdependent responses to ATP, $\mathrm{HZ}$ and basic calcium phosphate crystals $^{30-32}$. Activation of this pathway initiates a signalling cascade that changes cellular metabolism, apoptosis, autophagy and inflammatory responses. We confirmed that crystals induced phosphorylation of AKT in BMDM and THP1, and XOR inhibition decreased the observed levels (Fig. $5 c, d$ ). The role of the PI3K-AKT-mTOR pathway was further confirmed, as Ly294002, wortmannin, AKTx inhibitor and rapamycin all significantly decreased IL1 $\beta$ secretion in OCP-stimulated BMDM (Fig. 5a,b). In addition, XO and the PI3K/AKT pathway were upstream of mitochondrial ROS production, as febuxostat, and Ly294002 significantly decreased mitochondrial ROS detected by mitoSOX fluorescence in OCP-stimulated BMDM (Fig. 5e). Using JC-10 to assess mitochondrial depolarization, we confirmed that febuxostat prevented OCPinduced membrane changes (Fig. $5 \mathrm{f}$ ). Specificity of mitochondrial ROS detection by mitoSOX was verified using apocynin (Supplementary Fig. 2).

Interestingly, although XOR co-localized to both the mitochondria and the cytoplasm, OCP exposure did not affect
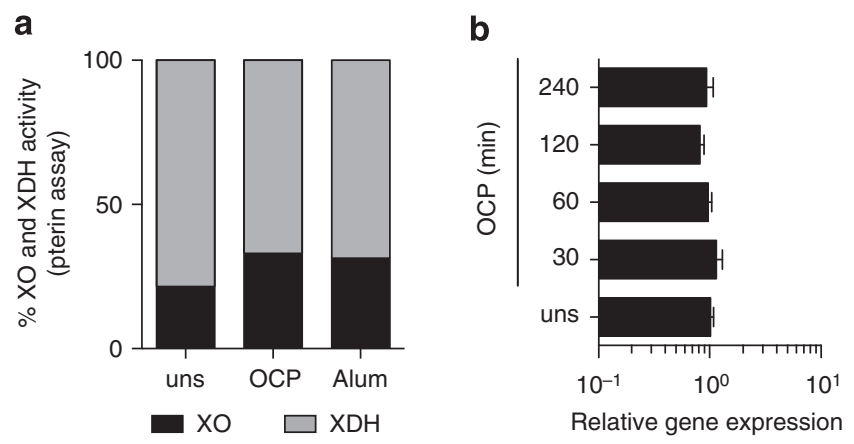

c

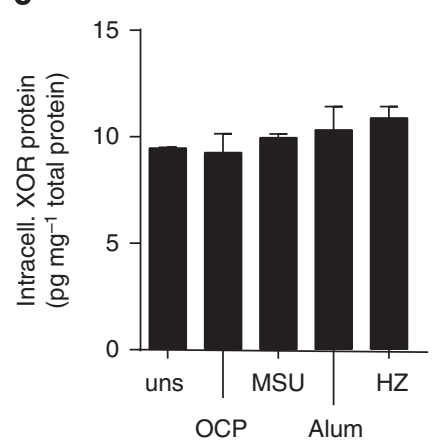

d

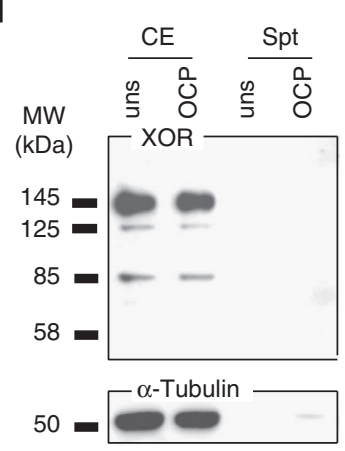

Figure 4 | XOR was not modulated at RNA and protein levels. In vitro C57BL/6 BMDM (Pam3Cys (P3C) or LPSup primed), and THP1 (PMA primed) were stimulated with OCP and MSU at $250 \mu \mathrm{g} \mathrm{ml}^{-1}, 500 \mu \mathrm{g} \mathrm{ml}^{-1}$ Alum and $200 \mu \mathrm{g} \mathrm{ml}^{-1} \mathrm{HZ}$. (a) The $\% \mathrm{XO}$ and XDH activity was measured in BMDM cell lysates using the pterin assay; (b) RNA transcript level of XOR by $\mathrm{QRT} T-\mathrm{PCR}$ in P3C-primed BMDM. Expression levels were quantified using the $2^{\triangle \Delta C T}$ method, with $T b p$ as a reference gene. (c) Total XOR protein levels in P3C-primed BMDM measured by ELISA. (d) THP1 cells stimulated with OCP crystals and the $\mathrm{CE}$, and supernatants blotted against anti-human XOR antibody or $\alpha$-tubulin. 
a

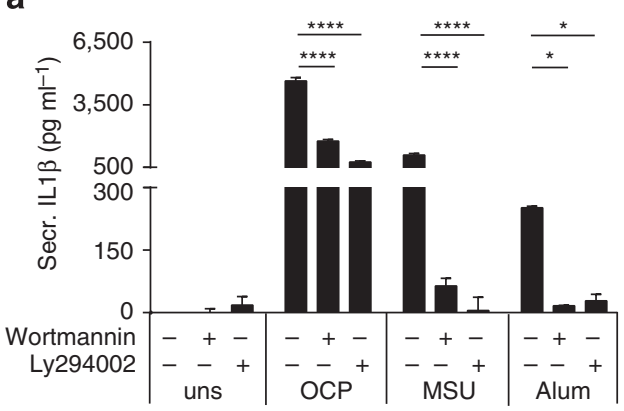

b

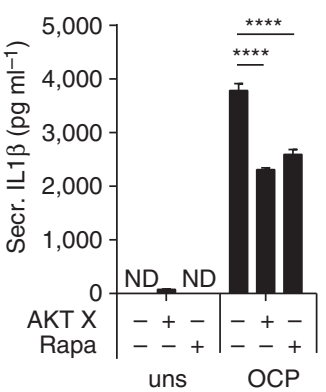

C

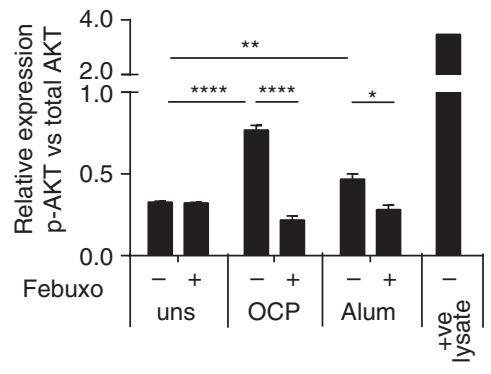

e

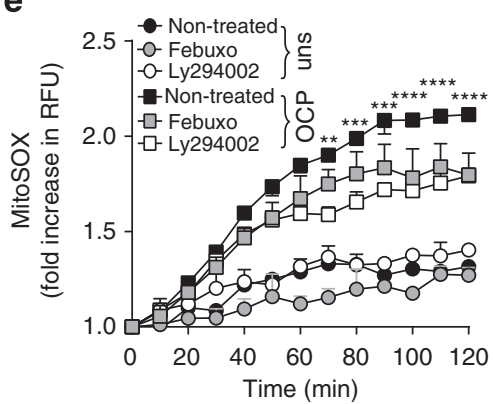

d

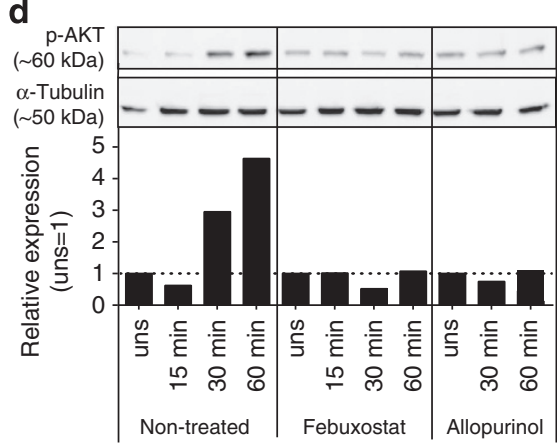

f

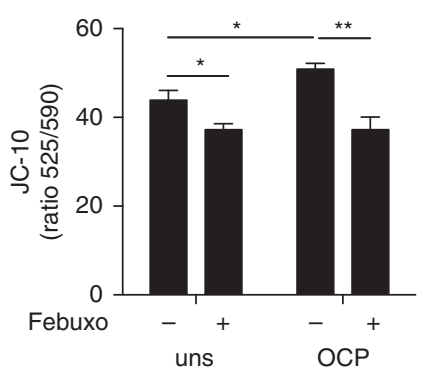

Figure 5 | Crystal-mediated XOR activation induces the PI3K-AKT-mTOR pathway and mitochondrial ROS production. In vitro BMDM (Pam3Cys primed), and THP1 cells (PMA primed) were pretreated with $200 \mu \mathrm{M}$ febuxostat, $10 \mu \mathrm{M}$ Ly294002, $10 \mu \mathrm{M}$ Wortmannin, $10 \mu \mathrm{M}$ AKTx, or Rapamycin (Rapa), and stimulated with OCP or MSU at $250 \mu \mathrm{g} \mathrm{ml}^{-1}$, or $500 \mu \mathrm{g} \mathrm{ml} \mathrm{m}^{-1}$ Alum. (a,b) IL $1 \beta$ protein secretion measured in BMDM. (c) Relative expression levels determined by ELISA of phosphorylated ( $p$-) AKT (ser473) over total AKT levels in BMDM at $1 \mathrm{~h}$. (d) THP1 cell extracts analysed for phosphorylated AKT (p-AKT) at ser473, and $\alpha$-tubulin by western blot. Relative protein levels determined by band intensity quantification, and given as p-AKT over $\alpha$-tubulin, normalized with unstimulated cells being 1. (e) Mitochondrial ROS detected by MitoSOX, results given as RFU at $T=60$ min over $T=0$. (f) Mitochondrial potential of BMDM was measured using the ratio of monomeric $\left(E_{525}\right)$ to multimeric JC-10 (Em 590$)$. Experiments were performed at $6 \mathrm{~h}$; data are representative of at least two experiments. Results are expressed as mean \pm s.e.m. Significance was determined at ${ }^{\star} P \leq 0.05$, ${ }^{\star \star} P \leq 0.01$, ${ }^{\star \star \star} P \leq 0.005$ and ${ }^{\star \star \star \star} P \leq 0.0001$ by analysis of variance for all panels

the staining pattern (Fig. 6a). Further investigation saw that XOR was present in both compartments, but with a predominance of the $\mathrm{XO}$ form in the mitochondrial fraction. Both the cytoplasmic and the mitochondrial fractions were functional, and febuxostat inhibitable XOR activity was found (Supplementary Fig. 3). Mitophagy and autophagy negatively regulate inflammasome-mediated IL1 $\beta$ secretion $10,33,34$. Thus, we tested whether XOR inhibition changed the cell's homeostatic balance to induce autophagic vesicle formation, which would reduce the pool of proIL1 $\beta$ available for cleavage. The degree of autophagy remained unchanged after the treatment of primed, unstimulated BMDM with febuxostat as detected by immunocytochemistry using an antibody specific for the lipidated type-II form of LC3B. Yet, significant increases in autophagy were observed after AKTx and rapamycin administration (Fig. 6b).
These results imply that $\mathrm{XO}$ formation is essential for oxidative stress generation, and inflammasome activation via the PI3KAKT-mTOR pathway, following exposure to crystals.

Soluble activators of the inflammasome activate XO. As the inflammasome can be activated within macrophages following exposure to soluble PAMPs and DAMPs, we evaluated whether XOR was involved. Primed BMDM, stimulated with LPSc (crude extract of LPS), induced significantly more XO activity as compared with unstimulated controls, and when febuxostat, NAC or Ly294002 was added prior to stimulation there was a significant reduction in secreted IL1 $\beta$ (Fig. 7a,b). As with our in vivo crystalinduced peritonitis model, we performed in vivo studies in mice to confirm our in vitro work. Febuxostat administration, prior to LPSc injection, reduced the urate and IL1 $\beta$ detected in peritoneal washes (Fig. 7c). Finally, IL1 $\beta$ secretion induced by LPS, ATP and 
a
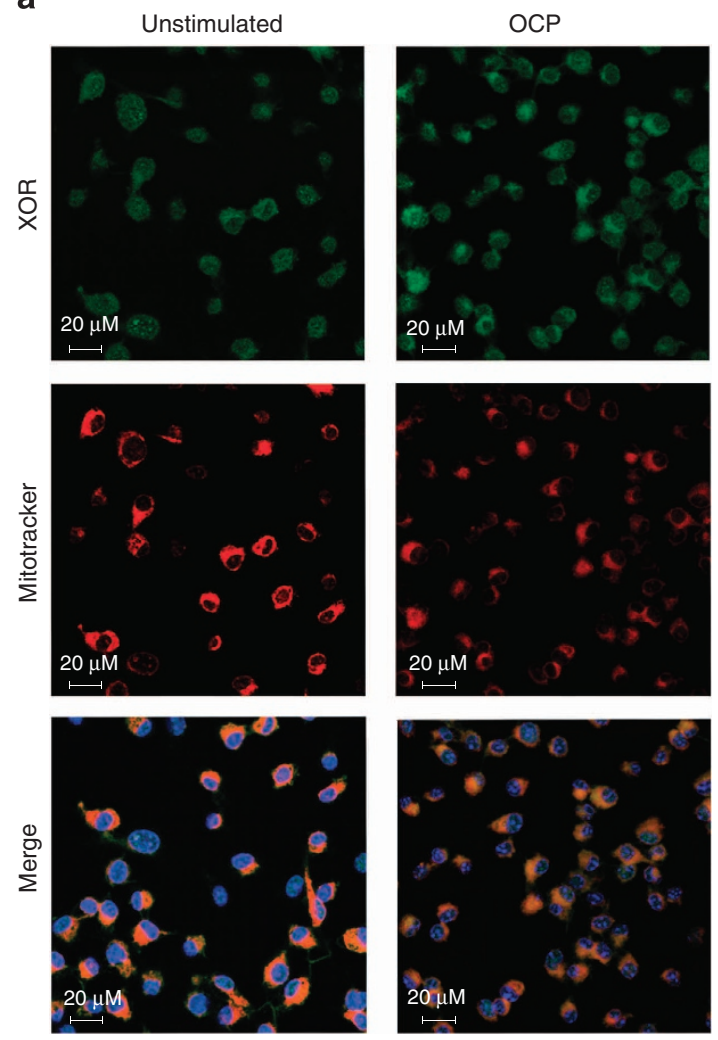

b
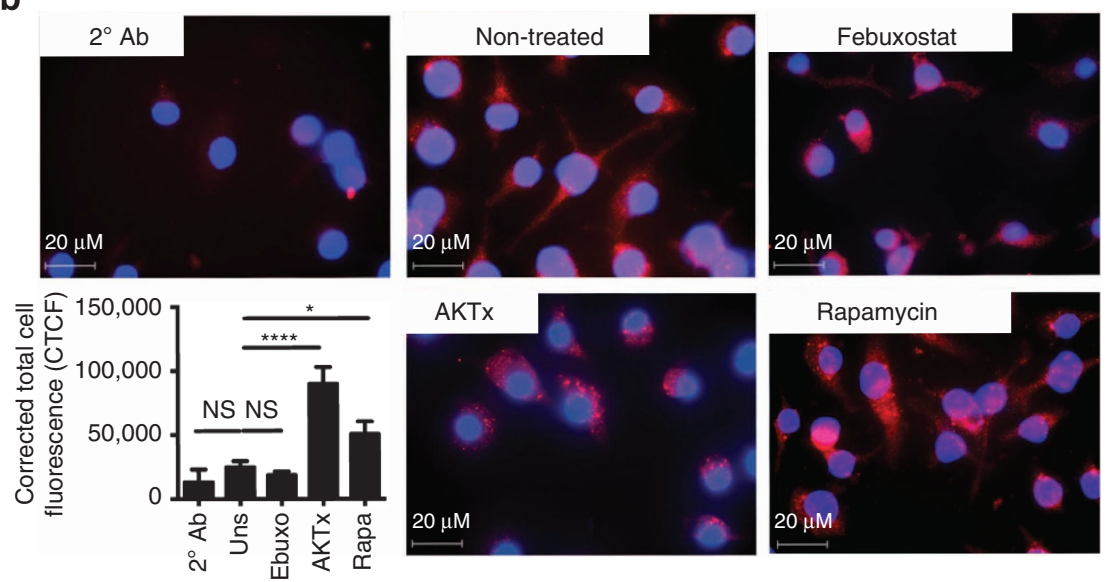

Figure 6 | Crystal-mediated XOR activation induces the PI3K-AKT-mTOR pathway and mitochondrial ROS production. (a) Colocalization in BMDM of fluorescein isothiocyanate-labelled anti-XOR antibody, Mitotracker and counterstained with 4',6-diamidino-2-phenylindole (DAPI). Images visualized at $\times 630$. Scale bars are indicated. Results are representative of several fields of view with similar results after $6 \mathrm{~h}$ of stimulation. (b) Autophagic vesicle formation in unstimulated BMDM after $2 \mathrm{~h}$ treatment were detected by LC3B Antibody labelled with TRITC, and counterstained with DAPI. Images were visualized at $\times 400$ and are representative of several fields of view with similar results. (c) Corrected total cell fluorescence (CTCF) was calculated for each cell in multiple fields of view for LC2B/TRITC red fluorescence. Results are expressed as mean \pm s.e.m. and significance was determined at ${ }^{\star} P \leq 0.05$ and ${ }^{\star \star \star \star} P \leq 0.0001$ by ANOVA. NP, not performed. NS, not significant.

nigericin was markedly impaired after febuxostat or AKTx treatment (Fig. 7d).

These results confirm our hypothesis that XOR activation is essential for inflammasome activation and IL1 $\beta$ cytokine secretion.

\section{Discussion}

The formation of ROS by phagocytes is critical for bacterial killing, but it can also regulate cellular signalling cascades during immune activation ${ }^{35}$. The inhibition of NLRP3-inflammasome-mediated IL1 $\beta$ secretion by free-radical scavengers such as apocynin demonstrates the importance of this signalling pathway ${ }^{36}$. Multiple intracellular sources of ROS exist, including NOX complexes, the mitochondria ${ }^{37}$ and last but not least, through activity of the oxidase form of XOR. Although it was initially thought that inflammasome ROS was generated by NOX, this idea was refuted by evidence from studies using human and mice cells deficient for components of the NOX complex. 


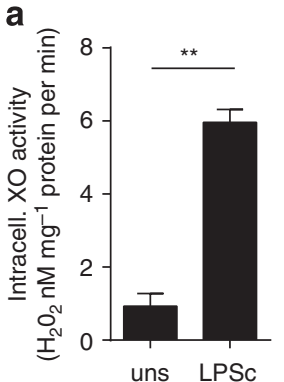

C

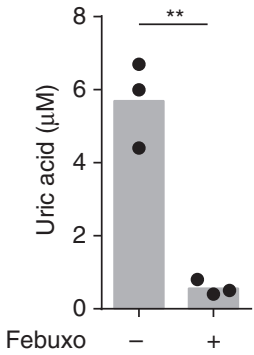

b

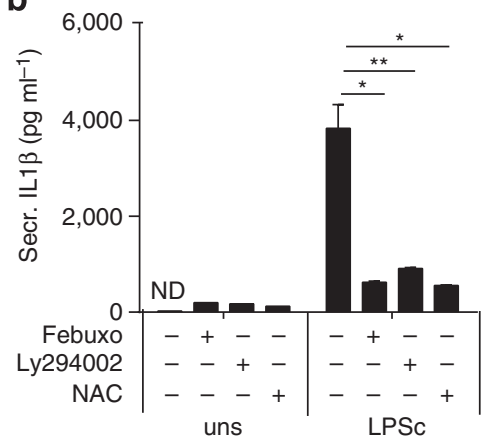

d

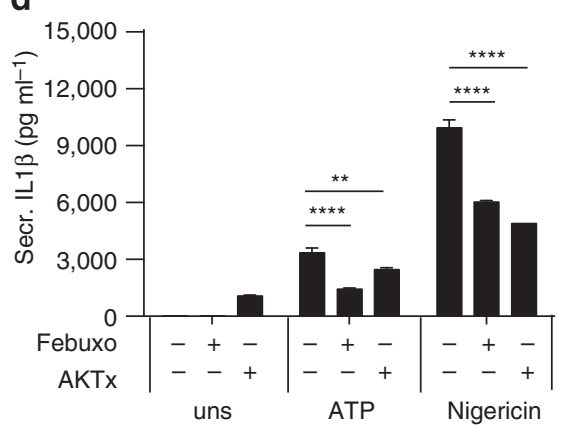

Figure 7 | Inhibition of XOR impairs IL1及 secretion triggered by soluble inflammasome inducers and in vivo. In vitro C57BL/6 BMDM (Pam3Cys primed) pretreated with $200 \mu \mathrm{M}$ febuxostat, $\mathrm{N}$-acetyl cysteine (NAC), $10 \mu \mathrm{M}$ Ly294002 or $10 \mu \mathrm{M}$ AKTx inhibitor and stimulated with a crude extract of $1 \mu \mathrm{g} \mathrm{ml} \mathrm{m}^{-1}$ LPS, $2.5 \mu \mathrm{M}$ nigericin or $5 \mathrm{mM}$ ATP. (a) XO activity measured in cell extracts at $1 \mathrm{~h}$. (b) IL1 $\beta$ protein secretion measured in BMDM at $6 \mathrm{~h}$. (c) Mice injected intraperitoneally with LPSc with or without $1 \mathrm{mM}$ Febuxostat for $6 \mathrm{~h}$. Urate levels and IL1 $\beta$ were measured in cell-free washes (two pooled experiments). (d) IL1 $\beta$ protein secretion measured in BMDM after $15 \mathrm{~min}$ stimulation for ATP and $6 \mathrm{~h}$ for nigericin. Data are representative of at least two experiments. Results are expressed as mean \pm s.e.m. Statistical significance was determined at ${ }^{\star} P \leq 0.05,{ }^{\star \star} P \leq 0.01$ and ${ }^{\star \star \star \star} P \leq 0.0001$ by analysis of variance $(\mathbf{b}, \mathbf{d})$ or the $t$-test $(\mathbf{a}, \mathbf{c})$.

Our data showed that the XO form of XOR is the major source of ROS in macrophages that mediates NLRP3 inflammasome activation. XOR is an evolutionarily conserved, constitutively expressed enzyme involved in purine degradation that catalyses the conversion of hypoxanthine or xanthine to UA. It is a homodimer; each $145-\mathrm{kDa}$ subunit has three domains: an $\mathrm{N}$-terminal $20-\mathrm{kDa}$ domain containing two $\mathrm{Fe}-\mathrm{S}$ centres, a central $40-\mathrm{kDa}$ flavin adenine dinucleotide domain and a C-terminal $85-\mathrm{kDa}$ molybdopterin-binding domain. XOR is predominantly a $\mathrm{NAD}^{+}$-dependent dehydrogenase $(\mathrm{XDH})$, but upon oxidative stress, it can be converted to the oxygenase form. Both forms generate $\mathrm{UA}$, but the $\mathrm{XO}$ form also produces superoxide and hydrogen peroxide. The conversion of $\mathrm{XDH}$ to $\mathrm{XO}$ can be by irreversible proteolytic cleavage of the $145-\mathrm{kDa}$ protein to an $85-\mathrm{kDa}$ form, or by reversible sulfhydryl modification that changes the electron acceptor sensitivity of the flavin adenine dinucleotide domain through tertiary structure conformational modifications ${ }^{38-40}$.

Our results show that $\mathrm{XO}$ inhibition attenuates NLRP3 inflammasome activation, as evidenced by impaired caspase 1 and IL1 $\beta$ secretion in macrophages in vitro and in vivo. There was no effect of febuxostat on activation of the AIM2 inflammasome (Supplementary Fig. 4), indicating that this mechanism may be specific for NLRP3 activation. We used XO inhibitors in our studies rather than siRNA, as we could administer the inhibitors after cellular priming, thus excluding that our results were to due an effect on $M \phi$ priming via TLR stimulation. Although, mutated and deficient XOR mice exist, they die prematurely making in vivo experimentation difficult ${ }^{41,42}$.

We suggest that the conversion of XOR to XO occurs via reversible oxidation of cysteine residues, rather than proteolytic cleavage of the protein into the $85-\mathrm{kDa}$ form, as we found no change in the molecular weight of XOR when the inflammasome was activated by OCP crystals, and because dithiothreitol treatment of BMDM converted a large proportion of $\mathrm{XO}$ activity to XDH. XOR protein was localized to the cytoplasm as well as to the mitochondria by confocal microscopy, so both compartments may participate in ROS generation. As there are no XO-specific antibodies available, we cannot definitively confirm that it is the $\mathrm{XO}$ form that is found in both locations. However, cell fractionation experiments showed that both cytoplasmic and mitochondrial fractions had measurable XOR activities, in support of our hypothesis.

We determined that XOR-dependent ROS also activates the AKT-PI3K-mTOR pathway in macrophages ${ }^{30-32}$. Cellular oxidative stress is linked to the AKT-PI3K-mTOR pathway. ROS inactivates the regulatory subunit PTEN (phosphatase and tensin homologue deleted on chromosome 10), which enables downstream activation of AKT, and the mTOR complex 1 refs 43,44 . In our in vitro stimulation experiments, febuxostat inhibited the phosphorylation of AKT, reduced mitochondrial ROS and impacted processing and IL1 $\beta$ secretion by caspase1. As autophagy reduces inflammasome-dependent IL1 $\beta$ secretion and is negatively regulated by the AKT pathway ${ }^{10,45-47}$, we wondered whether our results were because febuxostat increases autophagy. Yet, we found no evidence of increased autophagy when cells were exposed to febuxostat and concluded that the observed responses were due to impaired ROS generation. Furthermore, febuxostat did not interfere with calcium flux (Supplementary Fig. 5).

We also investigated whether it was UA, the other product of XOR activity, that mediated cellular activation. UA crystals are potent inflammasome activators, yet little is known about the 
effects of soluble urate on immune responses. Despite observing high intracellular urate levels after crystal stimulation, IL1 $\beta$ secretion remained high in cells from uricase transgenic macrophages, or when extracellular uricase was added to the culture system. Also, macrophages treated with soluble urate failed to show augmented IL1 $\beta$ secretion, even at concentrations seen in clinical hyperuricemia in man. When we combine these results with the observation that there is no clear urate transport mechanism in macrophage, this suggests to us that soluble UA is not responsible for inflammasome activation. However, it is possible that when large amounts of UA are released from dying cells, urate crystals could be formed, which then activate the inflammasome as a particulate stimulus via XOR activation. We have attempted to confirm this by polarizing light microscopy, but were unable to detect urate crystals within dying cells or in the supernatant.

Besides gout, hyperuricemia is also a risk factor for hypertension and cardiovascular disease ${ }^{48}$, but the mechanisms are not well understood. High urate levels can be pro-inflammatory to the endothelium and renal tubules ${ }^{16,48,49}$. Our current results could explain these associations. We propose that hyperuricemia is an indicator of increased $\mathrm{XO}$ activity that leads to enhanced ROS formation and pro-inflammatory cell responses. This will not only affect IL $1 \beta$ secretion from macrophages, but through its actions on the PI3K-AKT pathway, affect other cellular responses. These interactions could account for the associations previously observed in epidemiological studies, and also why XO inhibition by allopurinol has a beneficial effect on hypertension and stroke $e^{50-52}$.

On the basis of our results, we suggest that XOR inhibitors may improve conditions that are linked to inflammasome activation, such as atherosclerosis ${ }^{28,52,53}$. However, careful exploration of their mechanism of action is needed, as UA can be an important antioxidant in the circulation. Current XOR inhibitors inhibit both the $\mathrm{XDH}$ and $\mathrm{XO}$ forms of $\mathrm{XOR}$, and are used principally to lower urate levels. To overcome this problem, the development of an XO-specific inhibitor that would impact ROS but leave XDH activity untouched is warranted. This would maintain urate levels but decrease the oxidative stress-dependent pathology of chronic inflammatory diseases.

\section{Methods}

Mice. C57BL/6 mice were purchased from Charles River. Intracellular uricase transgenic-intUOX-Tg mice and littermate controls (on a C57BL/6 background) were from K. Rock (University of Massachusetts, USA) ${ }^{18}$. All experiments and the housing of the mice adhered to the guidelines set by the 'Service de la consommation et des affaires vétérinaires du Canton de Vaud' for the humane use of laboratory animals with authorization from the state veterinarian. Female mice used in experiments were 8-10 weeks of age.

BMDM preparation and maintenance of THP1 cells. Bone marrow cells were incubated for 7 days on Petri dishes with 30\% L929 conditioned media, 20\% fetal bovine serum (PAA) in Dulbecco's modified Eagle's media (Life Technologies) to differentiate into BMDM. BMDM and THP1 cells were stimulated with complete RPMI (cRPMI) media (Life Technologies) with 10\% fetal bovine serum, $1 \%$ Hepes (Life Technologies) and 1\% penicillin-streptomycin (Sigma-Aldrich), or incomplete RPMI with $1 \%$ penicillin-streptomycin only).

\section{Human monocytes and macrophage generation from healthy donors.}

Peripheral blood was obtained from healthy donors after informed consent. Peripheral blood mononuclear cells were isolated by Ficoll-Hypaque (Life Technologies). Monocytes were purified by magnetic-associated cell sorting by negative selection. Differentiation used $50 \mathrm{ng} \mathrm{ml}^{-1}$ of recombinant human macrophage colony-stimulating factor (R\&D systems) in cRPMI.

XO inhibition and stimulation of cells. Sterile, pyrogen-free ( $\leq 0.01 \mathrm{EUper}$ $10 \mathrm{mg}$-by Limulus amebocyte cell lysate assay) OCP, and MSU crystals were synthesized as described previously ${ }^{54,55}$. Alum and $\mathrm{Hz}$ (Invivogen) were resuspended in PBS and sonicated prior to use. Primary cells (BMDM and huM $\varphi$ ) were primed with $100 \mathrm{ng} \mathrm{ml}^{-1}$ Pam3Cys or $20 \mathrm{ng} \mathrm{ml}^{-1}$ ultrapure LPS-LPSup (Invivogen) overnight or left unstimulated in cRPMI. THP1 cells were primed for $3 \mathrm{~h}$ with $300 \mathrm{ng} \mathrm{ml}^{-1}$ phorbol myristate acetate (PMA). Inhibitors used were: $250 \mu \mathrm{g} \mathrm{ml}^{-1}$ allopurinol (Sigma-Aldrich), $200 \mu \mathrm{M}$ febuxostat (Teijin Pharma Ltd.), $2.5 \mathrm{mM}$ apocynin (Sigma-Aldrich), $12.5 \mathrm{mM} \mathrm{NAC} \mathrm{(Sigma-Aldrich),} 20 \mu \mathrm{g} \mathrm{ml}^{-1}$ rasburicase (Sanofi), $10 \mu \mathrm{M}$ Wortmannin (Sigma-Aldrich), $10 \mu \mathrm{M}$ Ly294002 (Sigma-Aldrich), $10 \mu \mathrm{M}$ AKTx inhibitor (Calbiochem) and $50 \mathrm{nM}$ rapamycin (Sigma-Aldrich). To ensure that our results were due to the actions of the inhibitor on the cell, our non-treated controls always contained equal quantities of the resuspension vehicle of the inhibitors. For febuxostat, wortmannin, Ly294002 and AKTx this was dimethylsulphoxide (DMSO). Cells were stimulated using $250 \mu \mathrm{g} \mathrm{ml}^{-1} \mathrm{OCP}$ and MSU, $500 \mu \mathrm{g} \mathrm{ml}^{-1}$ Alum, $200 \mu \mathrm{g} \mathrm{ml}^{-1} \mathrm{~Hz}$ and $1 \mu \mathrm{g} \mathrm{ml}^{-1}$ crude LPS (Escherichia coli O111:B4-Sigma-Aldrich) for $6 \mathrm{~h}$, unless stated otherwise. Supernatants were collected, the cells harvested and protein or RNA analysed.

XOR activity and UA determination. Cell lysates were tested for XO activity (AAT Bioquest) and UA quantification (Invitrogen) using fluorescence assays. The amount of fluorescent resorufin is directly proportional to the amount of $\mathrm{H}_{2} \mathrm{O}_{2}$ generated during the respective enzymatic reactions. Fluorescence was measured at $\mathrm{Ex}_{540} \mathrm{Em}_{590}$ cutoff 590. The manufacturer's protocols were followed. The results from the in vivo OCP peritonitis model were expressed in RFUs and the intracellular XO levels in BMDM were expressed as $\mathrm{nM} \mathrm{H}_{2} \mathrm{O}_{2}$ per mg protein per min The pterin assay to discriminate between $\mathrm{XO}$ and $\mathrm{XDH}$ activity was performed as previously described ${ }^{29}$. Briefly, cell lysates of BMDM were placed into two different reaction mixes-one that measures XO activity using the conversion of $50 \mu \mathrm{M}$ pterin to isoxanthopterin, and the other that measures total XOR activity by using methylene blue to replace NAD + as the electron receptor. Fluorescence was measured at $345 / 390 \mathrm{nM}$. The results were calculated as the percentage of XO or $\mathrm{XDH}$ activity against the total XOR activity.

Cytokine and XOR protein quantification. Supernatants or protein lysates from cells were assayed using the IL1 $\beta$ enzyme-linked immunosorbent assay (ELISA) kit (eBioscience). XOR protein quantified using the anti-mouse XDH ELISA kit (USCN life sciences). All manufacturers' protocols were followed. The results were read at $450 \mathrm{~nm}$ using the Spectrax M5e (Molecular Devices). Caspase1 activity was measured using a fluorometric activity test that measures the amount of free 7-amino-4-trifluoromethylcoumarin (AFC) that has been cleaved from YVADAFC by active caspase1 within the cell. Fluorescence was detected at Ex $400 \mathrm{~nm}$ Em $505 \mathrm{~nm}$ (Biovision Inc.). Human caspase1 was measured by ELISA (eBioscience).

In vivo experiments. Female C57BL/6 mice were treated with Allopurinol $500 \mu \mathrm{g}$ per mouse, Febuxostat $1 \mathrm{mM}$ or rasburicase $20 \mu \mathrm{g} \mathrm{ml}-1$ or a DMSO vehicle control prior to injection with OCP crystals or LPSc in the peritoneal cavity. PBS alone was administered as a control. After $6 \mathrm{~h}$, mice were sacrificed, the peritoneal cavity washed with PBS and then analysed for urate, extracellular XO activity and IL1 $\beta$ by ELISA (eBioscience).

SiRNA knockdown of XOR. BMDM were transfected using the Amaxa nucleofector (Lonza AG). BMDM were transfected using either XOR-specific siRNA $5^{\prime}$ CCGAGGATTTCAAACCTTTA- $3^{\prime}$ or control siRNA (proprietary sequenceSI03650318) at $300 \mathrm{nM}$ (Qiagen). Knockdown efficiency was determined by quantitative real-time PCR and the XO activity assay.

Western blot. Cells were lysed in $0.5 \% \mathrm{NP}-40$ lysis buffer of $150 \mathrm{mM} \mathrm{NaCl}$, Tris$\mathrm{HCl}$ with EDTA-free protease inhibitor cocktail (Roche), and resuspended with Lammeli buffer. Blots were prepared using polyacrylamide gels, and nitrocellulose membranes using the Bio-Rad II system. Antibodies used were anti-human IL1 $\beta$ (1:1,000 dilution, Cell Signaling Technology), anti-human procaspase-1 (1:500 dilution, gift from R. Solari), Phospho-Akt ${ }^{\operatorname{Ser} 473}$ (1:2,000, Cell Signaling Technology) or $\alpha$-tubulin (1:2,000 dilution, Sigma-Aldrich), anti-human XDH antibody (1:2,000 dilution, $\mathrm{xAbcam}$ ) and anti-rabbit-horseradish peroxidase (HRP), and anti-mouse HRP (1:2.000 dilution, Jackson laboratories). Blots were revealed using the Las2000 system with the Westbright Iris ECL reagent (Advansta). Subcellular fractions were blotted with Anti-XOR (H-110, Santa Cruz Biotechnology, at 1:250 dilution), anti-Tom20 (FL-145, Santa Cruz Biotechnology, at 1:500 dilution) and anti- $\alpha$-tubulin (Sigma, at 1:5,000 dilution). Images were cropped for figure presentation. Complete images are available as Supplementary Figs.

ROS assays. Luminol-100 $\mathrm{nM}$ and $\mathrm{HRP}-5 \mathrm{UI} \mathrm{ml}^{-1}$ (Sigma-Aldrich) was added concurrently to the stimuli and luminescence measured after $60 \mathrm{~min}$ using the Tecan M200. Results were expressed as relative luminescence units. For DHE and MitoSOX experiments, reagents were resuspended in DMSO and cells were loaded with DHE or mitoSOX (Invitrogen) at $5 \mu \mathrm{M}$. Fluorescence was determined at $\mathrm{Ex}_{540}$ $\mathrm{Em}_{590}$. Results expressed as RFUs at end point minus $T=0$. Experiments used opaque tissue culture-treated 96-well plates (Greiner Bio-One), and performed in HBSS (Life Technologies). 
Quantification of AKT phosphorylation. AKT phosphorylation was measured in cell lysates using the InstantOne ELISA (eBioscience). The manufacturer's instruction was followed. Results expressed as the ratio of phospho-AKT ${ }^{\text {Ser473 }}$ versus total AKT.

Mitochondrial membrane potential assay using JC-10. JC-10 enters the mitochondria, where it is retained in multimeric form while the compartment remains polarized. During membrane depolarization the JC-10 is converted to the monomeric form. Briefly, JC-10 (AAT Bioquest) was added to cells coated onto a black microtiter plate. Cells were then stimulated as above in the presence of JC-10. After $5 \mathrm{~min}$, the fluorescence of the multimeric form (Ex540/590) and monomeric form $\left(\mathrm{Ex}_{490} \mathrm{Em}_{525}\right)$ were measured. Results were expressed using the ratio of 525/590.

Calcium flux measurement. BMDM were primed with Pam3Cys O/N, washed

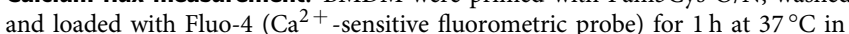
presence of febuxostat or EDTA (as a positive control for calcium flux inhibition). Baseline fluorescence was measured at $480 \mathrm{~nm} / 520 \mathrm{~nm}$. After stimulation with MSU crystals, fluorescence intensity was measured at $15 \mathrm{~s}$ interval over $15 \mathrm{~min}$.

Subcellular fractionation and western blot. Cellular fractionation of BMDM was performed as previously described ${ }^{1}$. (Briefly, BMDM were harvested, resuspended in hypotonic buffer (100 $\mathrm{mM}$ sucrose, $10 \mathrm{mM}$ HEPES and $1 \mathrm{mM} \mathrm{EDTA})$ and passed through a $30-\mathrm{G}$ needle and syringe, 1 in 12 volumes of hypertonic buffer (1.78 $\mathrm{M}$ sucrose, $10 \mathrm{mM}$ HEPES and $1 \mathrm{mM}$ EDTA) was added to homogenate, then centrifuged at $700 \mathrm{~g}$ and the supernatant harvested as cytoplasmic fraction.) The precipitated crude mitochondrial fraction was washed, and resuspended with isolation buffer ( $250 \mathrm{mM}$ sucrose, $10 \mathrm{mM}$ HEPES and $1 \mathrm{mM}$ EDTA). Protein was quantified using the bradford colorimetric assay (BCA) method (Bio-Rad laboratories). Equal protein quantities of the cytoplasmic and mitochondrial fractions were loaded on to an SDS-polyacrylamide gel electrophoresis gel.

Microscopy experiments. To study autophagy, BMDM were stimulated on glass microscope slides as above, fixed with $98 \%$ methanol for $10 \mathrm{~min}$ at $-20^{\circ} \mathrm{C}$ and permeabilized with $1 \times$ PBS and $0.5 \%$ Triton X-100 (Sigma-Aldrich). Cells were incubated overnight with LC3B antibody (diluted 1/400 Cell Signaling) in antibody diluent (BD Biosciences) and then stained with biotinylated anti-rabbit antibody (Vector) followed by streptavidin-TRITC (AbD Serotec). Slides were mounted with ProLong Gold Antifade Reagent with 4',6-diamidino-2-phenylindole (Life technologies). Images were taken using Upright Confocal Microscope Leica SP5 Tandem and visualized at $\times 1,000$ magnification. Quantification of autophagy was performed using ImageJ on all experimental conditions. Briefly, the corrected total cell fluorescence was calculated for each cell present within a field of view, and two independent fields of view were analysed with at least 18 cells measured in total. Corrected total cell fluorescence was calculated by measuring the integrated fluorescence density of the area of the cells-(the area of the cell $\times$ the mean fluorescence of the background). The results of all of the individual cells were pooled to give the mean and s.e.m. for each condition. This quantification was performed in ImageJ.

Colocalization experiments were performed with BMDM adhered to glass microscope slides and stimulated as above. Cells were stained with Mitotracker Red (Life Technologies) and fixed with $4 \%$ paraformaldehyde for $20 \mathrm{~min}$ at RT. Cells were permeabilized with 1x PBS and 0.5\% Triton X-100 (Sigma-Aldrich), and incubated overnight with anti-XOR Ab (5 ug ml ${ }^{-1}$, Santa Cruz Biotechnology Inc) in antibody diluent (BD Biosciences) followed by incubation with biotinylated antirabbit antibody (Vector) and then streptavidin-FITC (eBiosciences). Slides were mounted with ProLong Gold Antifade Reagent with 4',6-diamidino-2phenylindole (Life technologies). Images were taken using Upright Confocal Microscope Leica SP5 Tandem and visualized at $\times 630$ magnification.

UA uptake assay. BMDM were incubated with $167 \mu \mathrm{M}$ of ${ }^{14} \mathrm{C}$ UA in uptake buffer $(125 \mathrm{mM}$ sodium gluconate, $4.8 \mathrm{mM}$ potassium gluconate, $1.2 \mathrm{mM}$ potassium phosphate, monobasic, $1.2 \mathrm{mM}$ magnesium sulfate, $1.3 \mathrm{mM}$ calcium gluconate, $5.6 \mathrm{mM}$ glucose, $25 \mathrm{mM}$ Hepes, $\mathrm{pH}$ 7.3-all purchased from Sigma-Aldrich) for $20 \mathrm{~min}$. Ultima Gold scintillation fluid (PerkinElmer) was added and incubated $2 \mathrm{~h}$ for complete cellular lysis. Plate was read on a top count scintillation counter. Results were expressed as the radioactive counts per minute. Cell viability was controlled by Cell Titer Glo reagent (Promega).

PCR and quantitative real-time PCR. Briefly, cells were placed into Trizol (Invitrogen), RNA was extracted using the DirectZol RNA extraction kit (Zymoresearch) and reverse transcribed into complementary DNA using Superscript II (Invitrogen). Relative expression levels of RNA transcripts were determined using gene-specific primers, SYBR green and the LightCycler 480 system (Roche). Gene-specific primers were Tata-binding protein (Tbp): $5^{\prime}$-CCG TGAATCTTGGCTGTAAAC- $3^{\prime}$ and 5' $5^{\prime}$-TCCAGAACTGAAAATCAACGC-3'; Gapdh: 5'-CTCATGACCACAGTCCATGC-3', 3'-CACATTGGGGGTAGGAAC AC-5'; Urat1: $5^{\prime}$-ACACAGCCAGTCTCTTGATGGAGTG-3', $3^{\prime}$-CCGTGATGAG CCAGCGTGCC-5'; Abcg2: 5'-ACCAGTGTTTTTCCAGTGTGTCAGC-3', 3'-TC
CACCGTCTTCTTCAGTCCTAACA-5'; Glut9: 5'-GGGGCAGAGCCTGCAAGG TG-3' $3^{\prime}$-ACAGGTGACCCCTGCCACCC-5'; XOR: 5'-TAGAAGAAAGT TGGGGCTGTGCGG- $3^{\prime}$ and $5^{\prime}$-AGGAGCAGATGGGGGTCAAGCAG- $3^{\prime}$. Relative expression levels of genes of interest were calculated using $2^{\Delta \Delta \mathrm{CT}}$ method with $T b p$, and Gapdh as reference genes.

Graphical representation and statistical analyses. Figures and statistics were generated by Graphpad prism version 6. In vitro experiments were performed in replicate. Results expressed as mean and s.e.m. Statistical significance determined using two-tailed parametric $t$-tests or analysis of variance.

\section{References}

1. Gross, O., Thomas, C. J., Guarda, G. \& Tschopp, J. The inflammasome: an integrated view. Immunol. Rev. 243, 136-151 (2011).

2. Subramanian, N., Natarajan, K., Clatworthy, M. R., Wang, Z. \& Germain, R. N. The adaptor MAVS promotes NLRP3 mitochondrial localization and inflammasome activation. Cell 153, 348-361 (2013).

3. Hornung, V. et al. Silica crystals and aluminum salts activate the NALP3 inflammasome through phagosomal destabilization. Nat. Immunol. 9, 847-856 (2008).

4. Lu, B. et al. Novel role of PKR in inflammasome activation and HMGB1 release. Nature 488, 670-674 (2012).

5. Petrilli, V. et al. Activation of the NALP3 inflammasome is triggered by low intracellular potassium concentration. Cell Death Differ. 14, 1583-1589 (2007).

6. Lee, G. S. et al. The calcium-sensing receptor regulates the NLRP3 inflammasome through $\mathrm{Ca}(2+)$ and cAMP. Nature 492, 123-127 (2012).

7. Dostert, C. et al. Innate immune activation through Nalp3 inflammasome sensing of asbestos and silica. Science 320, 674-677 (2008).

8. Cassel, S. L. et al. The Nalp3 inflammasome is essential for the development of silicosis. Proc. Natl Acad. Sci. USA 105, 9035-9040 (2008).

9. Meissner, F. et al. Inflammasome activation in NADPH oxidase defective mononuclear phagocytes from patients with chronic granulomatous disease. Blood 116, 1570-1573 (2010).

10. Zhou, R., Yazdi, A. S., Menu, P. \& Tschopp, J. A role for mitochondria in NLRP3 inflammasome activation. Nature 469, 221-225 (2011).

11. Nakahira, K. et al. Autophagy proteins regulate innate immune responses by inhibiting the release of mitochondrial DNA mediated by the NALP3 inflammasome. Nat. Immunol. 12, 222-230 (2011).

12. Nomura, J. et al. Febuxostat, an inhibitor of xanthine oxidase, suppresses lipopolysaccharide-induced MCP-1 production via MAPK phosphatase-1mediated inactivation of JNK. PLoS ONE 8, e75527 (2013).

13. George, J. \& Struthers, A. D. Role of urate, xanthine oxidase and the effects of allopurinol in vascular oxidative stress. Vasc. Health Risk Manag. 5, 265-272 (2009).

14. Feig, D. I., Soletsky, B. \& Johnson, R. J. Effect of allopurinol on blood pressure of adolescents with newly diagnosed essential hypertension: a randomized trial. JAMA 300, 924-932 (2008).

15. Kao, M. P. et al. Allopurinol benefits left ventricular mass and endothelial dysfunction in chronic kidney disease. J. Am. Soc. Nephrol. 22, 1382-1389 (2011).

16. So, A. \& Thorens, B. Uric acid transport and disease. J. Clin. Invest. 120, 1791-1799 (2010).

17. Shi, Y., Evans, J. E. \& Rock, K. L. Molecular identification of a danger signal that alerts the immune system to dying cells. Nature 425, 516-521 (2003).

18. Kono, H., Chen, C. J., Ontiveros, F. \& Rock, K. L. Uric acid promotes an acute inflammatory response to sterile cell death in mice. J. Clin. Invest. 120, 1939-1949 (2010).

19. Orengo, J. M. et al. Uric acid is a mediator of the Plasmodium falciparuminduced inflammatory response. PLoS ONE 4, e5194 (2009).

20. Kool, M. et al. An unexpected role for uric acid as an inducer of T helper 2 cell immunity to inhaled antigens and inflammatory mediator of allergic asthma. Immunity 34, 527-540 (2011).

21. Nicholas, S. A., Bubnov, V. V., Yasinska, I. M. \& Sumbayev, V. V. Involvement of xanthine oxidase and hypoxia-inducible factor 1 in Toll-like receptor 7/8-mediated activation of caspase 1 and interleukin-1beta. Cell. Mol. Life Sci. 68, 151-158 (2011).

22. Griffith, J. W., Sun, T., McIntosh, M. T. \& Bucala, R. Pure Hemozoin is inflammatory in vivo and activates the NALP3 inflammasome via release of uric acid. J. Immunol. 183, 5208-5220 (2009).

23. Jin, C. et al. NLRP3 inflammasome plays a critical role in the pathogenesis of hydroxyapatite-associated arthropathy. Proc. Natl Acad. Sci. USA 108, 14867-14872 (2011).

24. Kool, M. et al. Cutting edge: alum adjuvant stimulates inflammatory dendritic cells through activation of the NALP3 inflammasome. J. Immunol. 181, 3755-3759 (2008).

25. Pazar, B. et al. Basic calcium phosphate crystals induce monocyte/macrophage IL-1beta secretion through the NLRP3 inflammasome in vitro. J. Immunol. 186, 2495-2502 (2011). 
26. Takano, Y. et al. Selectivity of febuxostat, a novel non-purine inhibitor of xanthine oxidase/xanthine dehydrogenase. Life Sci. 76, 1835-1847 (2005).

27. Klinenberg, J. R., Goldfinger, S. E. \& Seegmiller, J. E. The effectiveness of the xanthine oxidase inhibitor allopurinol in the treatment of gout. Ann. Intern. Med. 62, 639-647 (1965).

28. Duewell, P. et al. NLRP3 inflammasomes are required for atherogenesis and activated by cholesterol crystals. Nature 464, 1357-1361 (2010).

29. Beckman, J. S., Parks, D. A., Pearson, J. D., Marshall, P. A. \& Freeman, B. A. A sensitive fluorometric assay for measuring xanthine dehydrogenase and oxidase in tissues. Free Radic. Biol. Med. 6, 607-615 (1989).

30. Cruz, C. M. et al. ATP activates a reactive oxygen species-dependent oxidative stress response and secretion of proinflammatory cytokines in macrophages. J. Biol. Chem. 282, 2871-2879 (2007).

31. Cunningham, C. C. et al. Osteoarthritis-associated basic calcium phosphate crystals induce pro-inflammatory cytokines and damage-associated molecules via activation of Syk and PI3 kinase. Clin. Immunol. 144, 228-236 (2012).

32. Shio, M. T. et al. Malarial hemozoin activates the NLRP3 inflammasome through Lyn and Syk kinases. PLoS Pathog. 5, e1000559 (2009).

33. Harris, J. et al. Autophagy controls IL-1 \{beta\} secretion by targeting pro-IL1 beta\} for degradation. J. Biol. Chem. 286, 9587-9597 (2011).

34. Saitoh, T. et al. Loss of the autophagy protein Atg16L1 enhances endotoxininduced IL-1beta production. Nature 456, 264-268 (2008).

35. Pelletier, M., Lepow, T. S., Billingham, L. K., Murphy, M. P. \& Siegel, R. M. New tricks from an old dog: mitochondrial redox signaling in cellular inflammation. Semin. Immunol. 24, 384-392 (2012).

36. Latz, E., Xiao, T. S. \& Stutz, A. Activation and regulation of the inflammasomes. Nat. Rev. Immunol. 13, 397-411 (2013).

37. Murphy, M. P. How mitochondria produce reactive oxygen species. Biochem. J. 417, 1-13 (2009)

38. Nishino, T. et al. Mechanism of the conversion of xanthine dehydrogenase to xanthine oxidase: identification of the two cysteine disulfide bonds and crystal structure of a non-convertible rat liver xanthine dehydrogenase mutant. J. Biol. Chem. 280, 24888-24894 (2005).

39. Amaya, Y. et al. Proteolytic conversion of xanthine dehydrogenase from the $\mathrm{NAD}$-dependent type to the $\mathrm{O} 2$-dependent type. Amino acid sequence of rat liver xanthine dehydrogenase and identification of the cleavage sites of the enzyme protein during irreversible conversion by trypsin. J. Biol. Chem. 265, 14170-14175 (1990).

40. Enroth, C. et al. Crystal structures of bovine milk xanthine dehydrogenase and xanthine oxidase: structure-based mechanism of conversion. Proc. Natl Acad. Sci. USA 97, 10723-10728 (2000)

41. Ohtsubo, T., Rovira, I. I., Starost, M. F., Liu, C. \& Finkel, T. Xanthine oxidoreductase is an endogenous regulator of cyclooxygenase-2. Circ. Res. 95, 1118-1124 (2004).

42. Vorbach, C., Scriven, A. \& Capecchi, M. R. The housekeeping gene xanthine oxidoreductase is necessary for milk fat droplet enveloping and secretion: gene sharing in the lactating mammary gland. Genes Dev. 16, 3223-3235 (2002).

43. Carracedo, A. \& Pandolfi, P. P. The PTEN-PI3K pathway: of feedbacks and cross-talks. Oncogene 27, 5527-5541 (2008).

44. Leslie, N. R. et al. Redox regulation of PI 3-kinase signalling via inactivation of PTEN. EMBO J. 22, 5501-5510 (2003).

45. Shi, C. S. et al. Activation of autophagy by inflammatory signals limits IL-1beta production by targeting ubiquitinated inflammasomes for destruction. Nat Immunol. 13, 255-263 (2012).

46. Harris, J. et al. Autophagy controls IL-1beta secretion by targeting pro-IL-1beta for degradation. J. Biol. Chem. 286, 9587-9597 (2011)
47. Degtyarev, M. et al. Akt inhibition promotes autophagy and sensitizes PTENnull tumors to lysosomotropic agents. J. Cell. Biol. 183, 101-116 (2008).

48. Feig, D. I., Kang, D. H. \& Johnson, R. J. Uric acid and cardiovascular risk. N. Engl. J. Med. 359, 1811-1821 (2008).

49. Feig, D. I., Madero, M., Jalal, D. I., Sanchez-Lozada, L. G. \& Johnson, R. J. Uric acid and the origins of hypertension. J. Pediatr. 162, 896-902 (2013).

50. Sanchez-Lozada, L. G. et al. Treatment with the xanthine oxidase inhibitor febuxostat lowers uric acid and alleviates systemic and glomerular hypertension in experimental hyperuricaemia. Nephrol. Dial. Transplant 23, 1179-1185 (2008).

51. Muir, S. W. et al. Allopurinol use yields potentially beneficial effects on inflammatory indices in those with recent ischemic stroke: a randomized, double-blind, placebo-controlled trial. Stroke 39, 3303-3307 (2008).

52. Soletsky, B. \& Feig, D. I. Uric acid reduction rectifies prehypertension in obese adolescents. Hypertension 60, 1148-1156 (2012).

53. Kushiyama, A. et al. Xanthine oxidoreductase is involved in macrophage foam cell formation and atherosclerosis development. Arterioscler. Thromb. Vasc. Biol. 32, 291-298 (2012)

54. Narayan, S. et al. Octacalcium phosphate crystals induce inflammation in vivo through interleukin-1 but independent of the NLRP3 inflammasome in mice. Arthritis Rheum. 63, 422-433 (2011).

55. Akhtar, N. \& Haqqi, T. M. Epigallocatechin-3-gallate suppresses the global interleukin-1beta-induced inflammatory response in human chondrocytes. Arthritis Res. Ther. 13, R93 (2011).

\section{Acknowledgements}

We thank the following persons for providing reagents and assistance: Kenneth Rock for UOX-transgenic mice, Dr Mizuho Tamura (Teijin Pharma) for febuxostat, Catherine Ronet and Matteo Rossi for autophagy experiments and Payal Nanavati and David Hyndman for $\mathrm{C}^{14}$ urate transport assays. Professor Hans Acha-Orbea critically reviewed our manuscript. Funding for the work was provided by grants from the Swiss National Science Foundation (grant 310040_130085), the Institute of Arthritis Research and the Foundation RMR.

\section{Author contributions}

A.I. and N.B. conceived the main experiments, performed the experiments, analysed the data and wrote the manuscript. A.S. analysed the data and wrote the manuscript J.N., F.M., T.R., D.L., G.S. and J.N.M. contributed additional experimental data.

\section{Additional information}

Supplementary Information accompanies this paper at http://www.nature.com/ naturecommunications

Competing financial interests: The authors declare no competing financial interests

Reprints and permission information is available online at http://npg.nature.com/ reprintsandpermissions/

How to cite this article: Ives, A. et al. Xanthine oxidoreductase regulates macrophage IL1 $\beta$ secretion upon NLRP3 inflammasome activation. Nat. Commun. 6:6555 doi: $10.1038 /$ ncomms7555 (2015)

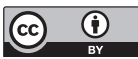

This work is licensed under a Creative Commons Attribution 4.0 International License. The images or other third party material in this article are included in the article's Creative Commons license, unless indicated otherwise in the credit line; if the material is not included under the Creative Commons license, users will need to obtain permission from the license holder to reproduce the material. To view a copy of this license, visit http://creativecommons.org/licenses/by/4.0/ 